\title{
Designing Relational Agents as Long Term Social Companions for Older Adults
}

\author{
Laura Pfeifer Vardoulakis ${ }^{1}$, Lazlo Ring ${ }^{1}$, Barbara Barry ${ }^{1}$, Candace Sidner ${ }^{2}$, \\ Timothy Bickmore ${ }^{1}$ \\ ${ }^{1}$ Northeastern University, College of Computer and Information Science \\ Boston, MA, USA \\ \{laurap, lring, bbarry, bickmore\}@ccs.neu.edu \\ ${ }^{2}$ Worcester Polytechnic Institute, Worcester, MA, USA \\ \{sidner\}@wpi.edu
}

\begin{abstract}
Older adults with strong social connections are at a reduced risk for health problems and mortality. We describe two field studies to inform the development of a virtual agent designed to provide long-term, continuous social support to isolated older adults. Findings include the topics that older adults would like to discuss with a companion agent, in addition to overall reactions to interacting with a remote-controlled companion agent installed in their home for a week. Results indicate a generally positive attitude towards companion agents and a rich research agenda for virtual companion agents.
\end{abstract}

Keywords: relational agents, social interfaces, social dialogue, wizard-of-oz study

\section{Introduction}

Studies have demonstrated that a lack of social support can have negative effects on the health and well-being of older adults [1], and older adults who face extreme isolation face significantly higher risks of mortality than their connected peers [2]. A recent meta-analysis estimates that $7-17 \%$ of older adults face social isolation and $40 \%$ experience loneliness [3] (social isolation refers to minimal contact with others, whereas loneliness refers to the subjective, usually negative, reactions to a person's social experiences [4]).

To address these problems, we are developing a virtual agent that can provide social support and wellness coaching to isolated older adults, in their homes, for months or years. This companion agent will be always on, always available, to provide a range of support interactions including: companionship dialogue, game co-play, exercise and wellness promotion, social activity tracking and promotion, facilitating connections with family and friends, and memory improvement tasks, among others.

To inform the design of this agent's dialogue capabilities, we conducted two field studies to determine what older adults would want to talk about with an in-home companion agent.

adfa, p. 1, 2011.

(c) Springer-Verlag Berlin Heidelberg 2011 


\section{Related Work}

\subsection{Social Technologies for Older Adults}

Many researchers have explored technologies that provide social activity scaffolding for older adults. In a longitudinal field study, Plaisant, et al., investigated shared, symmetric access for family calendars, as a way for remote, inter-generational family units to stay in touch and improve awareness surrounding daily activities [5]. Wearable and stationary devices that promote multimedia sharing with family and friends have also been designed to improve the social-connectedness of isolated adults [6].

Technologies designed specifically to provide companionship for older adults are an area of recent research. Leite, et al., developed a robotic companion designed for game co-play [7]. Wada, et al., have examined non-conversational therapeutic robots, and Klamer, et al., have examined the health benefits of in-home robots [8,9]. Cavazza, et al., explored the challenges surrounding a conversational agent companion that is able to intelligently ask about a user's day [10]. To explore how agents might be more useful than found in [9], this work undertakes a larger sample of participants in advance of full technology in participants' homes

\subsection{Wizard of Oz Methodologies}

In a Wizard of Oz (WOZ) study, a user interacts with a computer that is not autonomous, but rather one that is remotely-controlled by another human (often unbeknownst to the user) [11]. This technique is frequently used to explore human-computer interactions that are not possible with current technologies, such as full speech generation and understanding. WOZ methods have been used to explore companion agents, but only in single lab-based sessions [12]. Dow, et al., propose a new design for controlling embodied characters, one that blends both machine and human control [13]. We utilize this approach in the present work.

\subsection{Relational Agents}

Relational agents are autonomous, embodied agents designed to form relationships with their users by building trust, rapport, and therapeutic alliance over time [14]. These agents are typically designed as computer-animated, humanoid agents that simulate face-to-face dialogue with their users. Relational agents have been successfully used in health interventions, including several designed specifically for older adults [15]. When designing agents to promote social connectedness, relational agents provide several affordances. The agents are autonomous, since family, friends, and caregivers may not be available at all times.. The agents are conversational, because older adults with limited computer literacy are familiar and comfortable with this interaction format. Finally, the agents are relational, in that they are designed for companionship and long-term continual use, and thus can adapt to the changing nature of the socioemotional relationship users have with them. 


\section{Preliminary Exploration: Eldercare Companion Volunteers}

Our initial approach to understanding how elders might interact with companion agents was to meet with human role models: volunteers who provide periodic visitation to isolated older adults. We collaborated with a non-profit organization in Boston that manages a network of trained volunteers who provide support and assistance to elders and adults with disabilities. Members of our research staff first went through the orientation and training that is provided to new volunteers. We then conducted interviews with four volunteers and accompanied two of them on home visits to their elder "recipients".

The volunteers we interviewed were all women in their 20s (all trainees that we met were also female), and they all described their relationships with their recipients as friendships rather than service relationships. Volunteers visited their recipients once a week for approximately 1-2 hours. Recipients ranged in age from 60 to 97 and were mostly (75\%) female. All had mobility and other health problems, keeping three of them mostly at home except when their volunteers took them for walks during visits.

According to the volunteers, the recipients do most of the talking during visits, with storytelling by the elder taking up a significant portion of most interactions. When they are visiting in the elders' homes, the televisions are typically turned on, and chat topics include: storytelling, small talk (weather, etc.), topics occasioned by the television (during co-watching), reports of recent events and future plans ("relationship continuity" behaviors [16]), sports, the recipient's health, and the recipient's family. Two of the volunteers reported that their recipients craved more social contact with their family and friends, but that they didn't want to impose, so rarely initiated contact.

\section{WOZ Study: What do Older Adults Want to Talk About with a Companion Agent?}

To further understand how older adults would want to interact day-to-day with an inhome agent companion, we developed a virtual conversational agent that could be placed in the home and be remotely controlled by a researcher for a one-week duration. Since our primary objective was to understand the range of topics that older adults would want to talk about, we designed a research platform in which users could interact with the agent using unconstrained speech and nonverbal behavior.

\subsection{The Remote Wizard of Oz System}

The system runs on a dedicated computer in an older adult's home and is connected to the Internet. The agent talks using synthetic speech and synchronized nonverbal behavior, while the older adult converses using natural speech and non-verbal behavior that is captured via the computer's integrated microphone and webcam (Figure 1). The real-time audio and video of the older adult are streamed to a Wizard of Oz station, where a research assistant controls the agent responses by choosing pre-selected utterances and/or animation commands from the control-station software, or by manually 
typing utterances which are transmitted to the agent for real-time synthesis and animation.

Wizard commands are sent to the agent using an XML command language over a TCP/IP connection. Commands include specifications for spoken utterances, along with coordinating nonverbal behavior (hand gestures, eyebrow raises, head nods, posture shifts, gaze-aways) and facial displays of affect. Nonverbal behavior is generated using BEAT [17] or manually specified by the Wizard. Live audio and video of the participant was streamed to the Wizard using the Skype4Com ${ }^{1}$ API, and archived using VodBurner ${ }^{2}$. All interface actions taken by the Wizard were also logged with timestamps.

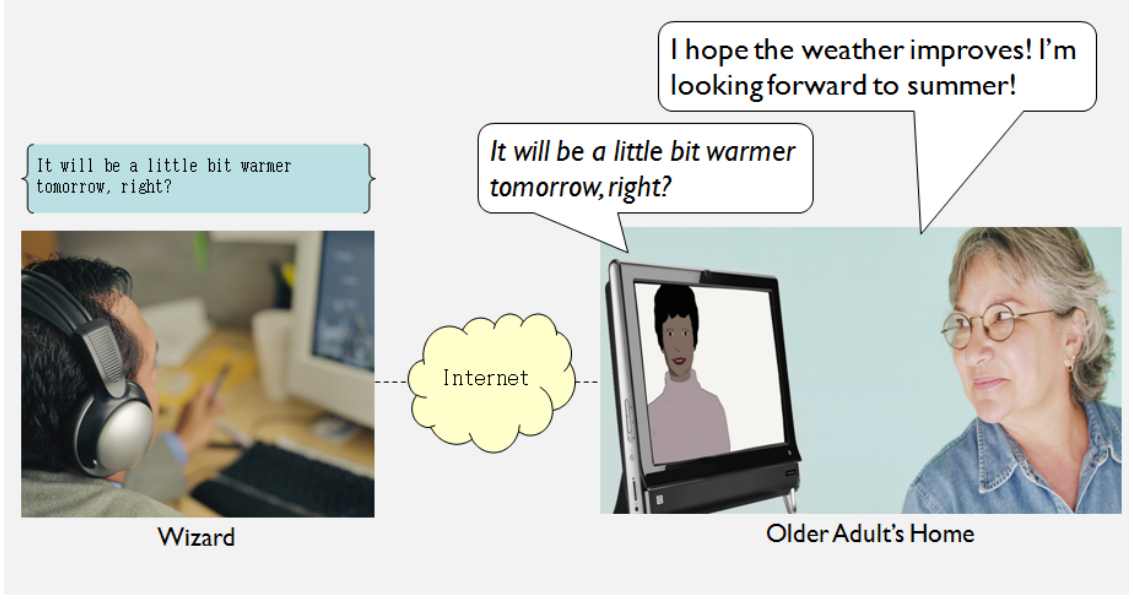

Fig. 1. Wizard-Agent Setup

\subsection{Methods}

Participants were recruited via an online job recruiting site. In order be eligible, participants needed to be 55 or older, speak English, live alone, and have a high-speed Internet connection. A research assistant met participants in their home to obtain informed consent, collect baseline measurements, install the agent computer and connect it to the Internet via the participant's existing network connection. Participants went through a simple introductory conversation with the agent with the research assistant, to make sure they were comfortable with the experience.

Participants were told that they could have daily conversations with the agent during a pre-scheduled 90-minute time window (when the wizard would be standing by). At the end of the week, a research assistant revisited the older adult in their home, to administer final measures, conduct a semi-structured interview about their experience,

1 http://developer.skype.com/accessories/skype4com

2 http://www.vodburner.com/ 
and collect the study computer. Study measures included socio-demographics, and the UCLA Loneliness Questionnaire [18] at intake, and an Agent Satisfaction Questionnaire at termination.

Four research assistants played the role of the Wizard. In keeping with the exploratory nature of the study, Wizards were given no instructions regarding what they should talk about with participants, only that they should have a "conversation”.

Privacy and Ethical Issues. Since the agent computer could be remote-controlled to begin video streaming by the wizard, participants were told how to tell the camera was active (an illuminated LED), and how to cover the camera if they wanted to ensure privacy. Although active deception is commonly used in Wizard of Oz studies so that participants think they are interacting with a fully automated system, we felt that carrying on such deception in a participant's home, over an extended period of time, was unwarranted. Participants were told in advance that the agent was not autonomous, but rather remote-controlled by a person at all times.

\subsection{Participants}

Twelve older adults (10 women, 2 men), aged 56-73 ( $m=62)$ participated in the weeklong study. Participants were mostly Caucasian; two were African-American. Participants were generally well-educated (all but one had some college) and came from diverse working backgrounds. Five participants were retired. Participants scored between 26-53 $(m=38.6, s d=8)$ out of a possible 80 on the UCLA loneliness measure, indicating that most participants reported low levels of loneliness.

\subsection{Results}

Participants had between 1 and 5 conversations with the agent $(m=3.5)$, with conversations lasting between 1.95 to 122.31 minutes $(m=28.33$, $s d=20.73)$.

Conversational Topics. Audio from all agent-participant dialogues was coded for high-level topics of conversation, along with the start and end of each topic boundary. A preliminary list of topics was created by consensus of the researchers following preliminary review of the dialogues. Coders added topics to the list if they felt that none of them adequately described a dialogue segment they were reviewing. In total, 70 distinct topics were discussed during the 41 agent-participant interactions (Appen$\operatorname{dix} I)$.

We find that the agent-participant conversations were highly individualized and that topics varied greatly, ranging from discussions of Family and Friends to Music, News and Fashion. Fifty-nine percent of all topics were not discussed by more than one participant (Table 1).

Despite this, there were many topics in common across participants. Table 2 presents examples of the most common topics. The three topics discussed by nearly all participants (other than greetings and farewells) were: Family, Weather and Storytell- 
ing. Discussion of Future Plans and asking Questions to the Agent also took place by more than half of the participants, ranging from inquiries about the agent's functionality to questions about its development trajectory and future applications. We also examined topics that were common across multiple conversations and found that, Storytelling, Weather, Future Plans, and Family were brought up in at least half of all Agent-Participant conversations.

Table 1. Agent-ParticipantConversation Information

\begin{tabular}{|c|c|c|c|c|}
\hline Participant & $\begin{array}{c}\text { Num } \\
\text { Conversations }\end{array}$ & $\begin{array}{c}\text { Avg Conv. } \\
\text { Length (Minutes) }\end{array}$ & Top Topics & $\begin{array}{l}\text { Time Spent } \\
\text { on Topic }\end{array}$ \\
\hline \multirow{3}{*}{1} & \multirow{3}{*}{4} & \multirow{3}{*}{41.62} & Storytelling & $26.30 \%$ \\
\hline & & & Miscellaneous & $19.13 \%$ \\
\hline & & & Food & $6.84 \%$ \\
\hline \multirow{3}{*}{2} & \multirow{3}{*}{4} & \multirow{3}{*}{12.34} & Miscellaneous & $31.12 \%$ \\
\hline & & & Report & $14.16 \%$ \\
\hline & & & Future Plans & $10.20 \%$ \\
\hline \multirow{3}{*}{3} & \multirow{3}{*}{5} & \multirow{3}{*}{14.87} & Storytelling & $14.62 \%$ \\
\hline & & & Wizard of $\mathrm{Oz}$ & $13.19 \%$ \\
\hline & & & Future Plans & $10.08 \%$ \\
\hline \multirow{3}{*}{4} & \multirow{3}{*}{4} & \multirow{3}{*}{17.33} & Storytelling & $60.12 \%$ \\
\hline & & & Future Plans & $9.97 \%$ \\
\hline & & & Opinions & $6.68 \%$ \\
\hline \multirow{3}{*}{5} & \multirow{3}{*}{5} & \multirow{3}{*}{50.05} & Television & $12.45 \%$ \\
\hline & & & Greeting & $12.44 \%$ \\
\hline & & & Storytelling & $9.70 \%$ \\
\hline \multirow{3}{*}{6} & \multirow{3}{*}{3} & \multirow{3}{*}{22.66} & Sports & $41.44 \%$ \\
\hline & & & Agent & $11.95 \%$ \\
\hline & & & Weather & $6.14 \%$ \\
\hline \multirow{3}{*}{7} & \multirow{3}{*}{2} & \multirow{3}{*}{24.55} & Travel & $15.36 \%$ \\
\hline & & & Daily Activities & $11.94 \%$ \\
\hline & & & Habits & $11.34 \%$ \\
\hline \multirow{3}{*}{8} & \multirow{3}{*}{3} & \multirow{3}{*}{20.10} & Questions to Agent & $12.31 \%$ \\
\hline & & & Storytelling & $12.03 \%$ \\
\hline & & & Goodbye & $11.22 \%$ \\
\hline \multirow{3}{*}{9} & \multirow{3}{*}{3} & \multirow{3}{*}{17.53} & Questions to Agent & $27.96 \%$ \\
\hline & & & System & $13.99 \%$ \\
\hline & & & Greeting & $9.33 \%$ \\
\hline \multirow{3}{*}{10} & & & Storytelling & $21.56 \%$ \\
\hline & 4 & 26.28 & Wellness & $16.30 \%$ \\
\hline & & & Family & $13.18 \%$ \\
\hline & & & Storytelling & $18.50 \%$ \\
\hline 11 & 4 & 47.59 & Agent & $16.01 \%$ \\
\hline & & & Exercise/Wellness & $14.21 \%$ \\
\hline & & & Family & $35.10 \%$ \\
\hline 12 & 1 & 54.77 & Agent & $21.38 \%$ \\
\hline & & & Miscellaneous & $9.39 \%$ \\
\hline
\end{tabular}


Table 2. Examples of frequent conversation topics (Tanya is the name of the agent)

\begin{tabular}{|c|c|}
\hline Topic & Example \\
\hline Family & $\begin{array}{l}\text { "I'm the oldest in my family ... I have a younger sister ..." - P7 } \\
\text { "I had to mail my grandson his weekly letter..." -P10 }\end{array}$ \\
\hline Weather & $\begin{array}{l}\text { "I'm doing well - I just came back and it's freezing out! I had to } \\
\text { go out and do a bunch of errands and it's so cold out!"-P10 }\end{array}$ \\
\hline Storytelling by elder & $\begin{array}{l}\text { "Would you like me to tell you about working on my Great-Aunt's } \\
\text { tobacco farm when I was a kid? ..." - P1 }\end{array}$ \\
\hline Future Plans & $\begin{array}{l}\text { P11: "Would you like to talk again tomorrow?" Agent:"Yes I } \\
\text { would." P11: "So would I." Agent: "What time are we on for?” } \\
\text { P11: "Well the afternoon,..." }\end{array}$ \\
\hline Questions to the Agent & $\begin{array}{l}\text { "Tanya, did the computer school design you? Or whose project } \\
\text { are you?" -P8 } \\
\text { "Do you have facial expressions, Tanya?...oh, a smile, great!" - } \\
\text { P11 }\end{array}$ \\
\hline
\end{tabular}

Conversation Topics of Specific Importance to Older Adults. Several topics were identified that are of particular importance to the design of companion agents for older adults (Table 3 ).

Activity identification and planning. Participants discussed activities as past events, new activities and future plans. While all participants mentioned lifestyle activities (e.g. reading, walking, seeing friends) those who scored as the least lonely (P11, P9) demonstrated more activity planning (Table 3. 1a \& 1b). Some planning statements included specific details connoting commitment, such as picking up bus schedules or reaching consensus with activity partners, while other planning statements expressed positive or negative sentiment about an event, either in anticipation or reflection. Studies in psychology and neuroscience have demonstrated the broad health benefits of cognitive enrichment activities and physical exercise for aging adults [19,20]. While a generic increase in activity improves health, amplified benefit is obtained by tailoring for engagement [21], variety of cognitive demand [22] and framing health messages in interactive systems for older adults [23]. Personalization of activity planning by virtual agents to best support older isolated adults requires detailed re-search into activity planning habits of older adults. As virtual agents are engaged in long-term interactions with users, enabling detailed user models, activity recommendations can be honed in support of the greatest individual health benefit.

Character strength disclosures and attitudes toward aging. Participants offered repeating statements revealing their character strengths [24]. Attitudes toward aging were less explicit than character strength disclosures (Table 3, 2a \& 2b). Distancing from negative attributes of aging was more prevalent than direct statements about positive aging. Three participants distanced themselves from "old people" who were sedentary or ruminative about their physical ailments. Identification of positive and negative attitudes towards aging would present an opportunity for intervention. Longevity studies show that a positive attitude toward aging (e.g., that aging offers wisdom and more 
free time rather than memory loss and loneliness) increases life expectancy by 7.5 years on average [25].

Family history and social ties. Our connections to others can be expressed in many forms, from personal narratives to calendars and to-do lists (Table 3, 3a \& 3b). Participants recounted stories about family and friends providing fodder for reconstructing their social networks. Personal narratives included self-explanation of physical proximity, frequency of interactions, and social support akin to network connections in the covey model [26]. Connectedness of some participants was closely linked to community-based, scheduled events. For older isolated adults, being able to understand and utilize networks of support can mitigate isolation [27]. Six participants explicitly defined others as sources of and recipients of help, further defining the roles of people in their social network. Virtual agents may be to help older adults create new social ties and maintain existing ones to meet their health needs.

Table 3. Topics Important for Older Adults

\begin{tabular}{|c|c|}
\hline Topic & Example Utterances \\
\hline 1a. Activity identification & $\begin{array}{l}\text { "When I'm traveling I enjoy shopping, ..." - P11 } \\
\text { "Now it's golf, which is a lot easier for me. Well not to do well } \\
\text { in but at least to participate in" - P6 }\end{array}$ \\
\hline 1b. Activity planning & $\begin{array}{l}\text { "...once it gets cold, it's a whole different kind of a flow in } \\
\text { terms of planning and travel".- P5 } \\
\text { "Maybe that could be my goal...to make sure I go to the danc- } \\
\text { ing tonight. Is that okay" - P11 }\end{array}$ \\
\hline 2a. Character strengths & $\begin{array}{l}\text { "I have to be on the move." (Vitality)- P1 } \\
\text { "I went to a fundraiser for charity to raise money for an or- } \\
\text { phanage." (Altruism)- P9 }\end{array}$ \\
\hline 2b. Attitudes toward aging & $\begin{array}{l}\text { "... some seniors have nothing better to do than to just sit } \\
\text { around and just gossip and you know." - P1 } \\
\text { "Being retired is new to me. That's why I roam around so } \\
\text { much." - P2 } \\
\text { "I think in this country unlike other countries older people } \\
\text { aren't as valued and aren't as much a part of the community" - } \\
\text { P9 }\end{array}$ \\
\hline $\begin{array}{l}\text { 3a. Family and friend } \\
\text { histories }\end{array}$ & $\begin{array}{l}\text { "My mother's sister was married to a man in western mass and } \\
\text { they had a truck farm". - P1 }\end{array}$ \\
\hline 3b. Social ties & $\begin{array}{l}\text { "I just lost my dog Sam who is a Lab at age } 13 \text { about six } \\
\text { months ago and he was my best pal. - P8 } \\
\text { "It is interesting I don't know them particularly but I think we } \\
\text { feel a commitment to each other in the sense that if something } \\
\text { happens I'd feel comfortable calling any of them saying I'd } \\
\text { need help, and they'd be right there, even though we don't } \\
\text { socialize. - P11 }\end{array}$ \\
\hline
\end{tabular}


Participant Reactions to the Agent. Participants reported high levels of satisfaction with the agent and indicated that they were comfortable having her in their home (Table 4).

Table 4. Agent Satisfaction Measures and Scores

\begin{tabular}{|l|l|l|l|}
\hline Question & Anchor 1 & Anchor 7 & Mean (SD) \\
\hline How satisfied were you with Tanya? & Not at all & Very satisfied & $6(1.09)$ \\
\hline $\begin{array}{l}\text { How much would you like to continue } \\
\text { working with Tanya? }\end{array}$ & Not at all & Very much & $5.36(1.68)$ \\
\hline $\begin{array}{l}\text { Would you rather have talked to a person } \\
\text { than Tanya? }\end{array}$ & $\begin{array}{l}\text { Definitely } \\
\text { prefer a person }\end{array}$ & $\begin{array}{l}\text { Definitely } \\
\text { prefer Tanya }\end{array}$ & $4.08(1.78)$ \\
\hline $\begin{array}{l}\text { I feel comfortable having Tanya in my } \\
\text { home. }\end{array}$ & $\begin{array}{l}\text { Disagree com- } \\
\text { pletely }\end{array}$ & $\begin{array}{l}\text { Agree com- } \\
\text { pletely }\end{array}$ & $5.7(1.05)$ \\
\hline
\end{tabular}

We also conducted in-person, semi-structured interviews with participants to further explore their experience with the in-home agent. These interviews were audiorecorded, transcribed, and coded for themes.

All participants had something positive to say about their experience with the agent (Tanya); four participants (P1, P2, P10, P12) had extremely positive reactions. For many, Tanya provided a sense of companionship and support.

"Yeah and I thought that I was going to cry because it was like losing a friend after talking to her for so many days ...." -P1

"I was very pleasantly surprised to find that there was such a connection to what I knew was actually a computer generated human being ... It did not feel like fantasy land although I didn't have the delusion that I was really talking to a human person there. I mean I was and I wasn't but I felt a connection and as I told you before I feel that there was an accountability built in there. And support." - P2

Eight participants (P1, P3, P4, P5, P6, P7, P8, P12) reported some negative comments regarding their experience with Tanya. Most of the negative reactions had to do with the lack of realism, the static nature of the interactions and the simplicity of Tanya's abilities. A few participants simply did not feel a connection to Tanya, and one participant (P8) reported that the interactions with Tanya made her feel worse, because they made her realize that she lacked the human interactions and the friendships that she desired for her life.

Privacy. Four participants ( $\mathrm{P} 1, \mathrm{P} 4, \mathrm{P} 5, \mathrm{P} 6)$ expressed no privacy concerns with the agent in their home. On the other hand, 7 participants expressed strong privacy concerns (P3, P6, P7, P8, P9, P10, P12). These concerns mostly revolved around the use of the webcam and uncertainty about whether or not they were recorded. Another factor that increased concerns about privacy was that the computer screen was on all times, though dimmed most of the time. One participant (P6) ended up turning the 
computer to the side when it wasn't in use, in order to prevent the webcam from having any possible view of his home. Two other participants (P1, P12) stated that they strategically placed the computer in a location where the camera would only be able to view a very small space of their home.

The Wizard Effect. Participants reported that throughout the study, they were cognizant of the Wizard of Oz component. For a few (P1, P2, P4, P9), the wizard component was in the background, and they viewed their experience as interacting with Tanya. For several others, the wizard component was in the foreground, and for some, not knowing who was truly behind the interaction caused anxiety.

“Well, rationally, I knew that there was a person controlling Tanya but it didn't feel like that.” - P2

"I didn't know if it was one or more people behind the scenes. It made me uncomfortable that I didn't know who was listening or watching.” - P6

Always On. Finally, we asked participants about their potential desire to interact with the agent throughout the day, instead of during a restricted time frame. While many participants found it convenient to have a specific interaction time, a few expressed positive reactions to interacting with the agent freely throughout the day. However, many of those participants also cautioned that they would want a sense of control over the interactions and the ability to turn the system off, if necessary.

"I would just like to make sure that there is an understanding - such as, when you call someone on the phone and they tell you that this is not a good time to talk, you can call back at a time that is good to talk. The thing for me is that if [the agent was] here all the time I would like that accessibility to be able to have the companionship all the time, but I would like to make sure that it is set up so that I don't have to rearrange my schedule to talk to her. I would like to be able to start and stop talking whenever I want to." - P5

\section{Conclusion}

We found high levels of acceptance of and satisfaction with the in-home social support agent by older adults in the WOZ study, with many participants stating that it provided them with a sense of companionship. Across both field studies, we found that elders would like to tell stories to and discuss the weather, their family, and their future plans with a live-in companion. Storytelling is particularly interesting because it is the topic that elders in both studies spent the most time on. In the WOZ study, participants spent between 1.8 and 43.87 minutes $(m=16.98$, $s d=15.98)$ telling stories to the agent. This indicates that the ability of agents to share in a storytelling experience would be valued and utilized by older adults. We also found that discussion of topics important for the social support of elders—including Activity Planning, Attitudes Towards Aging, 
and Social Ties — may require especially nuanced dialogue, although WOZ participants did volunteer much of this information on their own.

As discussed in Section 4, this work does have limitations. The in-home video recording utilized for WOZ purposes made eight participants somewhat uncomfortable, thus, the data collected might not be representative of completely anonymous conversations with an agent.

Despite this limitation, these studies provide a research agenda of dialogues to emulate in companion agents designed to provide social support for older adults. Our next steps involve implementing and testing an autonomous companion agent that is able to conduct many of these conversations without the support of a human Wizard, integrating information from the Internet (weather conditions, sports scores) and sensors (motion, vision, prosody) to develop a system that is able to provide adaptive, tailored social support over months or years of operation.

Acknowledgments. We thank Connor Westfall, Colin Shaughnessy, Bridgette Collado, and Ashley Kline for their assistance with this study. This material is based upon work supported by the National Science Foundation under Grant No. 1012086. Any opinions, findings, and conclusions or recommendations expressed in this material are those of the authors and do not necessarily reflect the views of the National Science Foundation.

\section{References}

1. Bassuk S, Glass T, Berkman L (1999) Social Disengagement and Incident Cognitive Decline in Community-Dwelling Elderly Persons. Annals of Internal Medicine 131 (3):165-173.

2. Berkman L, Syme L (1979) Social networks, host resistance, and mortality: A nine-year follow-up study of Alameda county residents. American Journal of Epidemiology 109 (2):186-204.

3. Dickens A, Richards S, Greaves C, Campbell J (2011) Interventions targeting social isolation in older people: a systematic review. BMC Public Health 11 (1):647.

4. Grenade L, Boldy D (2008) Social isolation and loneliness among older people: issues and future challenges in community and residential settings. Aust Health Review 32 (3):468478.

5. Plaisant C, Clamage A, Hutchinson H, Bederson B, Druin A (2006) Shared family calendars: Promoting symmetry and accessibility. ACM Trans Comput-Hum Interact 13 (3):313-346.

6. Chen C-Y, Kobayashi M, Oh L ShareComp: sharing for companionship. In: CHI '05 extended abstracts on Human factors in computing systems, Portland, OR, USA, 2005. ACM, pp 2074-2078.

7. Leite I, Mascarenhas S, Pereira A, Martinho C, Prada R, Paiva A "Why can't we be friends? An empathic game companion for long-term interaction." In: Proceedings of the 10th international conference on Intelligent virtual agents, Philadelphia, PA, 2010. SpringerVerlag, pp 315-321. 
8. Wada K, Shibata T Robot Therapy in a Care House - Change of Relationship among the Residents and Seal Robot during a 2-month Long Study. In: Robot and Human interactive Communication, 2007. RO-MAN 2007. The 16th IEEE International Symposium on, 26-29 Aug. 2007 2007. pp 107-112.

9. Klamer T, Ben Allouch S Acceptance and use of a social robot by elderly users in a domestic environment. Pervasive Computing Technologies for Healthcare (PervasiveHealth), 2010.

10. Cavazza M, Raul Santos de la C, Turunen M How was your day?: A companion ECA. In: Proceedings of the 9th International Conference on Autonomous Agents and Multiagent Systems: Volume 1, Toronto, Canada, 2010. International Foundation for Autonomous Agents and Multiagent Systems, pp 1629-1630.

11. Kelley JF (1984) An iterative design methodology for user-friendly natural language office information applications. ACM Trans Inf Syst 2 (1):26-41.

12. Bradley J, Benyon D, Mival O, Webb N Wizard of $\mathrm{Oz}$ experiments and companion dialogues. In: Proceedings of the 24th BCS Interaction Specialist Group Conference, Dundee, United Kingdom, 2010. British Computer Society, pp 117-123.

13. Dow S, Mehta M, MacIntyre B, Mateas M Eliza meets the wizard-of-oz: blending machine and human control of embodied characters. In: Proceedings of the 28th international conference on Human factors in computing systems, Atlanta, Georgia, USA, 2010. ACM, pp 547-556.

14. Bickmore T, Caruso L, Clough-Gorr K, Heeren T (2005) 'It's just like you talk to a friend' relational agents for older adults. HCI and the Older Population 17 (6):711-735.

15. Bickmore T, Schulman D, Yin L (2010) Maintaining Engagement in Long-term Interventions with Relational Agents. Applied artificial intelligence : AAI 24 (6):648-666.

16. Gilbertson J, Dindia K, Allen M (1998) Relational Continuity Constructional Units and the Maintenance of Relationships. Journal of Social and Personal Relationships 15 (6):774-790

17. Cassell J, Vilhjálmsson H, Bickmore T BEAT: The Behavior Expression Animation Toolkit. In: SIGGRAPH '01, Los Angeles, CA, 2001. pp 477-486

18. Russell D, Peplau LA, Curtrona CE (1980) The revised UCLA lonelines scale: concurrent and discriminant validity evidence. Journal of Personality and Social Psychology 39:472480

19. Teri L, Lewinsohn PM (1982) Modifcation of Pleasant and Unpleasant Events Schedule for use with elderly. . Journal of Consulting and Clinical Psychology 50:444-445

20. Mahncke HW, Bronstone A, Merzenich MM (2006) Brain plasticity and functional losses in the aged: scientific bases for a novel intervention. In: Aage RM (ed) Progress in Brain Research, vol Volume 157. Elsevier, pp 81-109.

21. Sheldon KM, Lyubomirsky S (2006) How to increase and sustaing positive emotion: The effects of expressing gratitude and best possible selves. The Journal of Positive Psychology 1:73-78

22. Carlson M, Parisi J, Xia J, Xue Q, Reobok G, Bandeen-Roche K, Fried LP (2012) Lifestyle Activities and Memory: Variety may be the spice of life. Journal of the International Neuropsychological Socieity 18:286-294

23. Bickmore T, Schulman D, Yin L (2010) Maintaining engagement in long-term interventions with relational agents. Applied artificial intelligence: AAI 24 (6):648 
24. Peterson C, Seligman MEP (2004) Character strengths and virtues: a handbook and classification. Oxford University Press, Inc., New York, NY

25. Levy B (1996) Improving memory in old age through implicit self-stereotyping. Journal of Personality and Social Psychology 71 (6):1092-1107.

26. Antonucci TC, Akiyama H (1987) Social Networks in Adult Life and a Preliminary Examination of the Convoy Model. Journal of Gerontology 42 (5):519-527.

27. Hooyman N, Kiyak H (2009) Social Gerontology: a multidisciplinary perspective. 9th edn.

\section{Appendix I: Full List of Conversational Topics}

\begin{tabular}{|c|c|c|}
\hline Topic & Num Distinct Participants & Avg duration (seconds) \\
\hline Agent & 3 & 139.62 \\
\hline Books & 4 & 161.14 \\
\hline Boston & 2 & 56.88 \\
\hline Boston/New England & 6 & 92.46 \\
\hline Computers and Older Adults & 1 & 250.69 \\
\hline Daily activities & 5 & 56.48 \\
\hline Education & 1 & 40.95 \\
\hline Exercise and wellness & 3 & 172.33 \\
\hline Family & 11 & 150.02 \\
\hline Fashion & 1 & 37.13 \\
\hline Fitness & 1 & 59.26 \\
\hline Food & 5 & 153.75 \\
\hline Friends & 5 & 91.72 \\
\hline Future plans & 9 & 53.39 \\
\hline Goodbye & 12 & 43.92 \\
\hline Greeting & 12 & 66.52 \\
\hline Habits & 5 & 44.48 \\
\hline Health & 4 & 59.00 \\
\hline Hobbies & 1 & 17.02 \\
\hline Job & 1 & 109.87 \\
\hline life lessons, morals, ethics & 3 & 135.26 \\
\hline Loneliness & 1 & 36.80 \\
\hline Medical & 3 & 119.38 \\
\hline Miscellaneous & 7 & 94.07 \\
\hline Miscellaneous (articles) & 1 & 161.08 \\
\hline Miscellaneous (cartoons) & 1 & 76.14 \\
\hline Miscellaneous (casino) & 1 & 138.13 \\
\hline Miscellaneous (children) & 2 & 168.64 \\
\hline Miscellaneous (christmas) & 1 & 48.32 \\
\hline Miscellaneous (colors) & 1 & 72.85 \\
\hline Miscellaneous (computers) & 1 & 48.57 \\
\hline Miscellaneous (current events) & 1 & 56.91 \\
\hline Miscellaneous (flashmob) & 1 & 327.72 \\
\hline
\end{tabular}




\begin{tabular}{|c|c|c|}
\hline Miscellaneous (halloween) & 1 & 21.35 \\
\hline Miscellaneous (holidays) & 1 & 238.07 \\
\hline Miscellaneous (internet) & 1 & 109.64 \\
\hline Miscellaneous (plants) & 1 & 71.41 \\
\hline Miscellaneous (poker) & 1 & 104.99 \\
\hline Miscellaneous (Richmond) & 1 & 93.53 \\
\hline Miscellaneous (smiling) & 1 & 41.18 \\
\hline Miscellaneous (weekend) & 1 & 36.31 \\
\hline Movies & 3 & 192.99 \\
\hline Music & 1 & 69.68 \\
\hline New England & 1 & 35.80 \\
\hline New England/Boston & 1 & 122.26 \\
\hline News & 1 & 77.94 \\
\hline Opinions & 5 & 59.13 \\
\hline Participation in Research & 1 & 35.70 \\
\hline Personal & 4 & 58.36 \\
\hline Personal history & 3 & 56.42 \\
\hline Pets & 2 & 167.54 \\
\hline Politics & 2 & 120.75 \\
\hline Questions & 2 & 39.53 \\
\hline Questions for the agent & 8 & 67.67 \\
\hline Report & 6 & 60.61 \\
\hline Research on Computer Agents & 1 & 135.63 \\
\hline Sports & 6 & 180.15 \\
\hline Storytelling & 10 & 161.71 \\
\hline Surfing Internet & 1 & 41.93 \\
\hline Technology & 3 & 80.70 \\
\hline Television & 4 & 102.84 \\
\hline Thanksgiving & 1 & 18.48 \\
\hline Travel & 6 & 64.49 \\
\hline Weather & 11 & 40.23 \\
\hline Wellness & 5 & 87.81 \\
\hline Wellness Follow-up & 1 & 76.69 \\
\hline Wellness: Goal Setting & 1 & 114.74 \\
\hline Work & 4 & 109.00 \\
\hline WOZ & 5 & 78.61 \\
\hline WOZ: Ideas for use of system & 2 & 80.66 \\
\hline
\end{tabular}

